\title{
Indoxyl Sulfate Induces Mesangial Cell Proliferation via the Induction of COX-2
}

\author{
Shuzhen Li, ${ }^{1,2,3}$ Sijie Cheng, ${ }^{1,2,3}$ Zhenzhen Sun, ${ }^{1,2,3}$ Harr-keshauve Mungun, ${ }^{1,2,3}$ \\ Wei Gong, ${ }^{1,2,3}$ Jing Yu, ${ }^{1,2,3}$ Weiwei Xia, ${ }^{1,2,3}$ Yue Zhang, ${ }^{1,2,3}$ Songming Huang, ${ }^{1,2,3}$ \\ Aihua Zhang, ${ }^{1,2,3}$ and Zhanjun Jia ${ }^{1,2,3}$ \\ ${ }^{1}$ Department of Nephrology, Nanjing Children's Hospital, Nanjing Medical University, Nanjing, China \\ ${ }^{2}$ Institute of Pediatrics, Nanjing Medical University, Nanjing, China \\ ${ }^{3}$ Nanjing Key Laboratory of Pediatrics, Nanjing Children's Hospital, Nanjing Medical University, Nanjing, China
}

Correspondence should be addressed to Aihua Zhang; zhaihua@njmu.edu.cn and Zhanjun Jia; jiazj72@hotmail.com

Received 10 August 2016; Accepted 27 September 2016

Academic Editor: Vinod K. Mishra

Copyright (c) 2016 Shuzhen Li et al. This is an open access article distributed under the Creative Commons Attribution License, which permits unrestricted use, distribution, and reproduction in any medium, provided the original work is properly cited.

\begin{abstract}
Indoxyl sulfate (IS) is one of important uremic toxins and is markedly accumulated in the circulation of end stage renal disease (ESRD) patients, which might contribute to the damage of residual nephrons and progressive loss of residual renal function (RRF). Thus this study was undertaken to investigate the role of IS in modulating mesangial cell (MC) proliferation and the underlying mechanism. The proliferation of MCs induced by IS was determined by cell number counting, DNA synthase rate, and cell cycle phase analysis. COX-2 expression was examined by Western blotting and qRT-PCR, and a specific COX-2 inhibitor NS398 was applied to define its role in IS-induced MC proliferation. Following IS treatment, MCs exhibited increased total cell number, DNA synthesis rate, and number of cells in S and G2 phases paralleled with the upregulation of cyclin A2 and cyclin D1. Next, we found an inducible inflammation-related enzyme COX-2 was remarkably enhanced by IS, and the inhibition of COX-2 by NS398 significantly blocked IS-induced MC proliferation in line with a blockade of PGE2 production. These findings indicated that IS could induce $\mathrm{MC}$ proliferation via a COX-2-mediated mechanism, providing new insights into the understanding and therapies of progressive loss of RRF in ESRD.
\end{abstract}

\section{Introduction}

Preservation of residual renal function (RRF) is important not only for predialysis ESRD patients but also for the patients undergoing the dialysis. RRF is a well-established predictor of the outcome and survival rate in dialysis patients [1]. Prospective randomized trials of dialysis adequacy and many observational studies have confirmed that the loss of $\mathrm{RRF}$ is highly associated with the mortality and morbidity in peritoneal dialysis (PD) patients $[2,3]$. RRF in dialysis patients is pretty helpful in small-solute clearance, fluid balance, phosphorus control, and removal of middle-molecular uremic toxins, especially for the toxins relying on renal metabolism or tubular secretion, such as indoxyl sulfate (IS) $[2,4]$.

Evidence showed that serum concentration of IS was significantly elevated in ESRD patients [5]. IS is a protein-bound uremic toxin that derives from the metabolism of dietary tryptophan [6]. However, IS cannot be efficiently removed by conventional hemodialysis because of its high binding affinity to albumin in advanced chronic kidney disease (CKD) [7]. Thus, the urinary excretion of IS was considered to occur mainly by tubular secretion and glomerular filtration. The IS accumulated in serum accelerates tubular cell injury and induces subsequent interstitial fibrosis, thus acting as a nephrotoxin [5, 8-10]. Studies also indicated that IS could lead to complex redox alterations in mesangial cells (MCs) [11] and cell proliferation in vascular smooth muscle cells [12]. IS has been shown to have many pathological roles in uremia-related organ injuries. For example, it can increase the production of reactive oxygen species (ROS) and cause vascular wall remodeling and extracellular matrix deposition [13]. The MC proliferation and subsequent matrix synthesis could result in the glomerular impairment and RRF loss. However, 
the role of IS in mediating MC proliferation still needs evidence.

COX-2, an inducible isoform of COXs, is expressed in the macula densa of the juxtaglomerular apparatus, cortical thick ascending limb of Henle (cTAL) in the renal cortex, and interstitial cells in the renal medulla [14]. PGE2 as one of five major prostaglandins is synthesized by COX-2related enzyme cascade and regulates glomerular filtration, renin release in the renal cortex, and tubular absorption of sodium and/or water in the medulla [15]. Accumulating evidence indicated that COX-2 contributes to a number of inflammatory diseases $[16,17]$ possibly via PGE2-mediated mechanisms. Recently, a report demonstrated that COX2 was inducible in the MCs in response to sphingosine 1phosphate stimulation [18]. Thus, in the present study, we fully studied the roles of IS in MCs proliferation and COX2 regulation, as well as the role of COX-2 in the proliferative process of MCs challenged by IS.

\section{Materials and Methods}

2.1. Materials. IS was purchased from Sigma (St. Louis, MO). Dulbecco's modified Eagle's medium (DMEM), fetal bovine serum (FBS), penicillin-streptomycin, and trypsinEDTA solution were purchased from Gibco (Invitrogen, Grand Island, NY). Cyclin D1 mouse monoclonal antibody and cyclin A2 rabbit polyclonal antibody were from Abcam. COX-2 mouse monoclonal antibody was purchased from Cayman Chemicals (Ann Arbor, MI). Anti-GAPDH (ab9485) was provided by Cell Signaling Technology (Danvers, MA). The PGE2 enzyme immunoassay kit was from Cayman Chemicals (Ann Arbor, MI). COX-2 inhibitor, NS398, was bought from Beyotime (Shanghai, China).

2.2. MCs Culture. The mouse MC line HBZY-1 was obtained from the China Center for Type Culture Collection (CCTCC Wuhan, China). Cells were maintained at $37^{\circ} \mathrm{C}$ in a humidified $5 \% \mathrm{CO}_{2}$ atmosphere in DMEM which contained $5.6 \mathrm{mM}$ glucose, $10 \%$ fetal bovine serum (FBS; GIBCO), $100 \mathrm{U} / \mathrm{mL}$ penicillin, $100 \mathrm{mg} / \mathrm{mL}$ streptomycin, $44 \mathrm{mM} \mathrm{NaHCO}_{3}$, and $14 \mathrm{mM}$ 4-(2-hydroxy-ethyl)-1-piperazineethanesulfonic acid. After MCs were cultivated to $60 \%-70 \%$ confluence, they were treated with IS for $24 \mathrm{~h}$ at different doses $(0,250$, and $500 \mu \mathrm{M})$ with or without COX-2 inhibitor NS-398 treatment at a dose of $10 \mu \mathrm{M}$.

2.3. Cell Cycle Analysis. MCs were treated with vehicle and the indicated doses of IS with or without COX-2 inhibitor in serum-free DMEM for $24 \mathrm{~h}$. Cells were washed twice with PBS before digestion with $0.25 \%$ trypsin and fixed in $70 \%$ ethanol for at least $2 \mathrm{~h}$ at $4^{\circ} \mathrm{C}$. Then cells were collected by centrifugation, treated with RNase, and stained with propidium iodide by using cell cycle detection kit (KeyGEN, Shanghai, China). The number of cells in G1, S, and G2/M cell cycle phases was analyzed by flow cytometry (BD FACS Calibur flow cytometer, Bedford, MA), and data analysis was performed with modifit 3.0 software.
2.4. Quantitative Real-Time PCR. Total RNA was from cultured MCs by using a TRIzol reagent (TaKaRa) according to the manufacturer's protocol. Reverse transcription was performed using a PrimeScript RT reagent Kit (TaKaRa) according to the manufacturer's protocol. Oligonucleotides (cyclin D1: forward, 5'-CGCCCTCCGTTTCTTACTTC- $3^{\prime}$, and reverse, $5^{\prime}$-GCAGTCAGGGGAATGGTCT$3^{\prime}$; cyclin A2: forward, 5'-AAGATGCCCTGGCTTTTAGTG- ${ }^{\prime}$, and reverse, $5^{\prime}$-TAACATTCACTGGCTTTTCGTCT-3'; Cyclooxygenase-2: forward, $5^{\prime}$-AGGACTCTGCTCACGAAGGA- ${ }^{\prime}$, and reverse, $5^{\prime}$-TGACATGGATTGGAACAGCA-3'; and GAPDH: forward, $5^{\prime}$-GTCTTCACTACCATGGAGAAGG-3' ${ }^{\prime}$, and reverse, $5^{\prime}$-TCATGGATGACCTTGGCCAG-3 ${ }^{\prime}$ ) were designed using Primer 5 software (available at http://frodo.wi.mit.edu/) and synthesized by Invitrogen. Real-time PCR amplification was performed using the ABI 7500 Real-Time PCR Detection System (Foster City, CA) by using SYBR Premix Ex Taq (TaKaRa). The cycling program consisted of a preliminary denaturation $\left(95^{\circ} \mathrm{C}\right.$ for $\left.10 \mathrm{~min}\right)$, followed by 40 cycles $\left(95^{\circ} \mathrm{C}\right.$ for $15 \mathrm{~s}$ and $60^{\circ} \mathrm{C}$ for $1 \mathrm{~min}$ ). Relative gene expression of mRNA was normalized to GAPDH and calculated using the $\Delta \Delta \mathrm{Ct}$ method.

2.5. Western Blotting Analysis. At the indicated time points, MCs were rapidly washed with ice-cold PBS and lysed on ice in lysis buffer containing protease inhibitors. After centrifugation, the protein level was determined using a micro BCA protein assay kit with bovine serum albumin as a standard (Pierce, Thermo). Sixty micrograms of cellular proteins were separated by SDS-PAGE and transferred onto PVDF membranes (Bio-Rad). The membranes were blocked by TBS-T $(0.1 \%$ Tween 20 in TBS) containing $5 \%$ nonfat milk for $1 \mathrm{~h}$ at room temperature, and then incubated with primary antibodies directed against cyclin D1 (1:1000), cyclin A2 (1:500), and COX-2 (1:500) by overnight incubation at $4^{\circ} \mathrm{C}$, followed by the addition of HRP-labeled secondary antibodies at room temperature for $1 \mathrm{~h}$. GAPDH was used as an internal standard control. Band intensity was measured using Image J software (NIH, Bethesda, MD, USA).

2.6. Enzyme Immunoassay. Cell culture medium was centrifuged for $5 \mathrm{~min}$ at $12,000 \times \mathrm{g}$. The concentration of PGE2 in the medium was determined by enzyme immunoassay (Cayman Chemical), according to the manufacturers' instructions.

2.7. Data Analysis. Data are presented as means \pm SE. Statistical analysis was performed using ANOVA analysis followed by a Bonferroni posttest. $P<0.05$ was considered statistically significant.

\section{Results}

3.1. IS-Induced MCs Proliferation. To investigate whether IS could induce MC proliferation, we treated the MCs with IS at the doses of $250 \mu \mathrm{M}$ and $500 \mu \mathrm{M}$, respectively. Cell proliferation was firstly examined by direct cell counting under the 


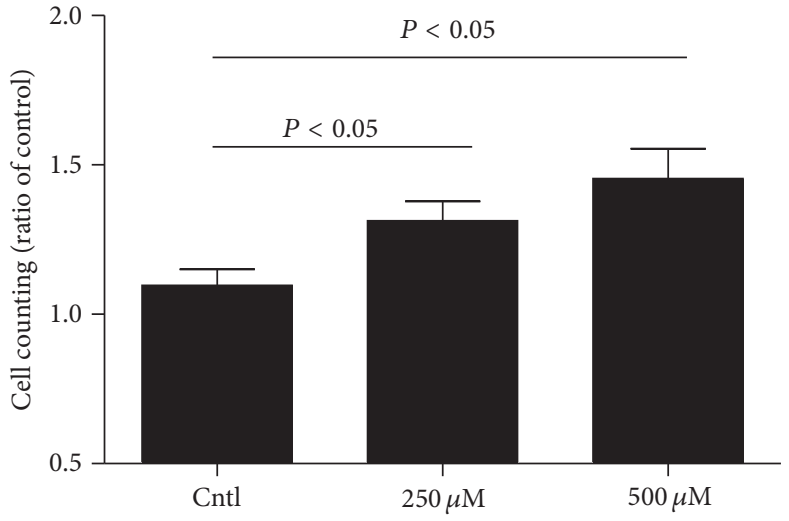

(a)

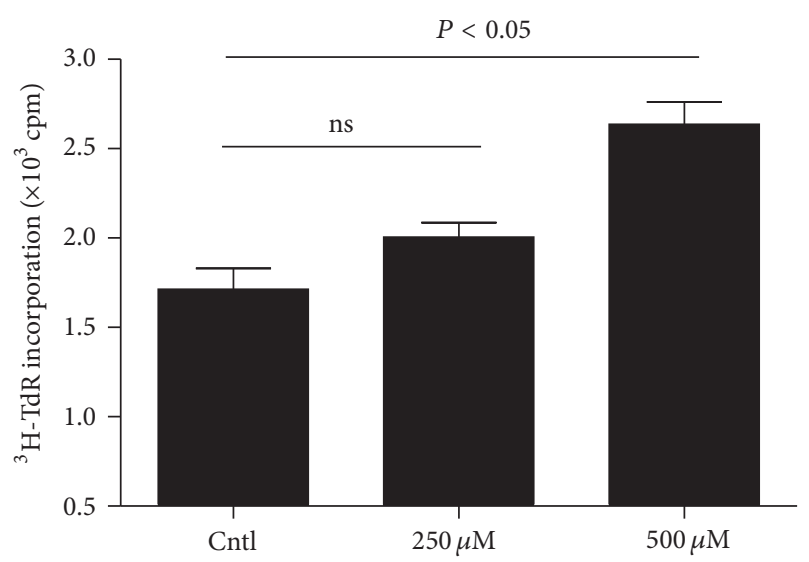

(b)

FIGURE 1: Effect of indoxyl sulfate (IS) on cell proliferation in MCs. After mesangial cells were cultivated to $60 \%-70 \%$ confluence, they were treated with IS for $24 \mathrm{~h}$ at different doses $(0,250$, and $500 \mu \mathrm{M})$ and cell proliferation was measured by cell counting (a) and [ $\left.{ }^{3} \mathrm{H}\right]$ thymidine $\left({ }^{3} \mathrm{H}\right.$-TdR) incorporation (b). Values are means $\pm \mathrm{SD} ; n=6$ in each group.

microscope and DNA synthesis rate $\left(\left[{ }^{3} \mathrm{H}\right]\right.$ thymidine uptake). As shown by the data, IS treatment for $24 \mathrm{~h}$ at the doses of 250 and $500 \mu \mathrm{M}$ moderately but significantly increased the total cell number by $21 \%$ and $35 \%$, respectively (Figure 1(a)). To further confirm this result, we examined DNA synthesis rate. Similarly, the amount of $\left[{ }^{3} \mathrm{H}\right]$ thymidine uptake in IStreated cells was also increased in a dose-dependent manner (Figure 1(b)). The data suggested that IS played a role in promoting mesangial cell proliferation.

3.2. IS-Induced Cell Cycle Progression in MCs. In order to further validate the conclusion shown above, we measured the cell cycle by flow cytometry in MCs exposed to different doses of IS. As shown by data, IS caused a moderate but significant decrease of MC numbers in the G1/G0 phase and increase of cell numbers in the $S$ phase (Figures 2(a)-2(f)). Cell cycle analysis revealed that IS can stimulate cell cycle progression in MCs.

3.3. IS Upregulated Cyclin D1 and Cyclin A2 in MCs. To further investigate the IS effect on MC proliferation, we measured the expressions of some key cell cycle-related proteins. Here we found that IS strikingly increased the mRNA levels of cyclin D1 and cyclin A2 in dose- and timedependent manners determined by qRT-PCR (Figures 3(a)$3(\mathrm{~d})$ ). By Western blotting, we observed a similar pattern of the protein expressions of cyclin D1 and cyclin A2 as their mRNA regulation (Figures 3(e)-3(h)).

3.4. IS Upregulated COX-2 Expression in MCs. To study the possible involvement of COX-2 in IS-induced MS proliferation, we measured COX-2 expression by Western blotting and qRT-PCR. As shown by data, COX-2 protein was dose-dependently elevated (Figures 4(a) and 4(b)). For the mRNA expression, $500 \mu \mathrm{M}$ but not $250 \mu \mathrm{M}$ increased COX2 mRNA level (Figure 4(c)). Using $500 \mu \mathrm{M}$ IS, we found a time-dependent induction of COX-2 mRNA expression
(Figure 4(d)). These results indicated that COX-2 could be induced by IS in MCs.

3.5. Silencing COX-2 Blocked IS-Induced Cell Cycle Progression in MCs. To examine the role of COX-2 in IS-induced proliferation in MCs, specific COX-2 inhibitor was applied to MCs. As shown in Figures 5(a) and 5(b), COX-2 inhibitor at 10 and $20 \mu \mathrm{M}$ lowered COX-2 expression. Further, we observed that COX-2 inhibition decreased the cell number in $S$ phase and increased cell number in G1/G0 phase (Figures $5(\mathrm{c})-5(\mathrm{j}))$. Moreover, we also found that COX-2 inhibitor markedly attenuated IS-induced cyclin D1 and cyclin A2 expression at mRNA levels (Figures 6(a) and 6(b)). These data highly suggested COX-2 played an important role in MC proliferation.

\subsection{Silencing COX-2 Significantly Blocked IS-Induced PGE2} Production. To further examine the efficiency of COX-2 inhibitor in the study, we measured PGE2 production in the medium. As shown by Figure 6(c), IS treatment increased PGE2 level by 3.8 -fold, which was entirely abolished by COX2 inhibition.

\section{Discussion}

RRF is very important for both predialysis and dialysis patients. Studies have demonstrated that the loss of RRF is a powerful predictor of mortality and morbidity in peritoneal dialysis (PD) patients [1-3]. RRF is pretty helpful for the removal of middle and larger molecular weight toxins $[2,4]$. IS, as one of the most known uremic toxins, is markedly accumulated in the serum of dialysis patients and accelerates the progression of disease $[6,19]$. In this study, we found that IS could moderately but significantly stimulate MC proliferation via a COX-2-mediated mechanism, which might contribute to the progressive loss of RRF. 


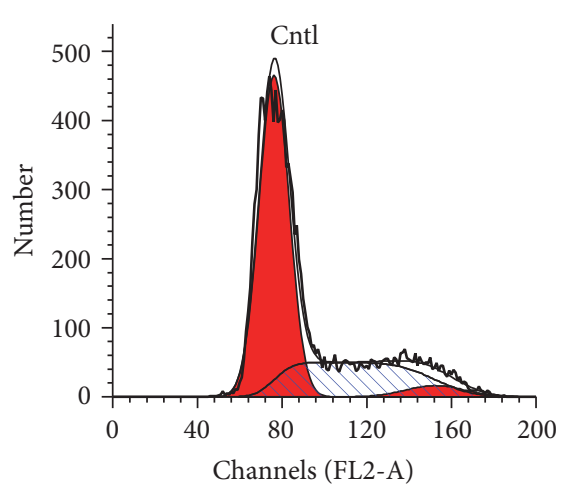

$\square$ Dip G0-G1 $\quad \square$ Dip S
$\square$ Dip G2-M

(a)

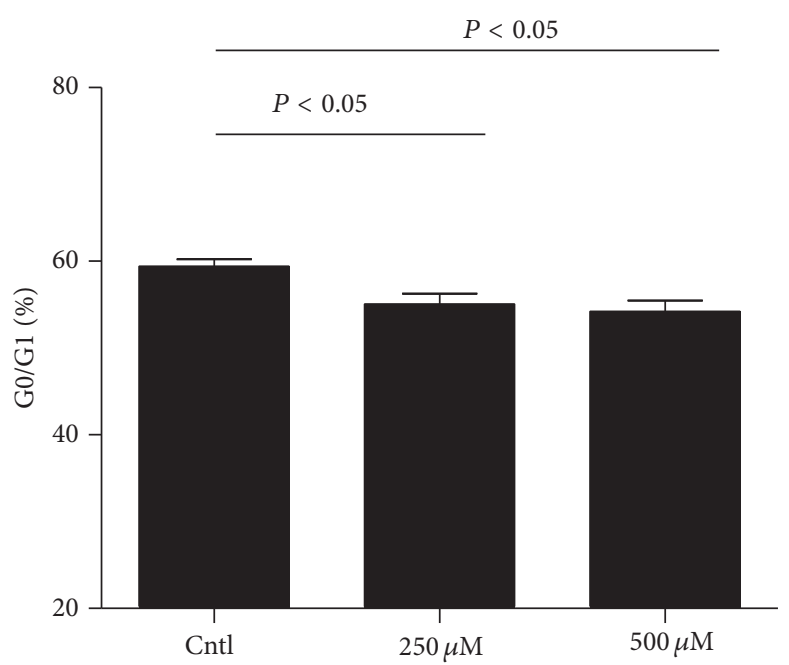

(d)

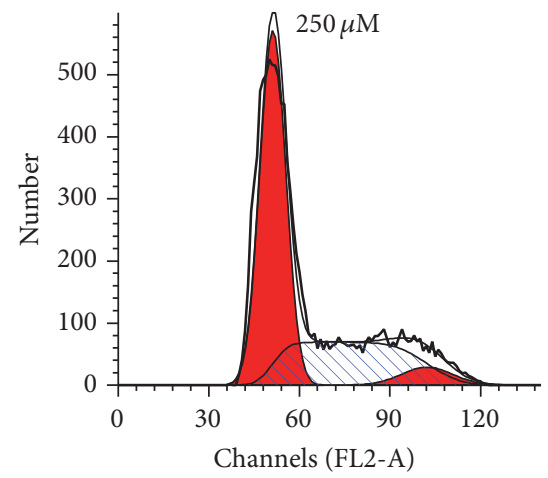

$\square$ Dip G0-G1 $\square$ Dip S

$\square$ Dip G2-M

(b)

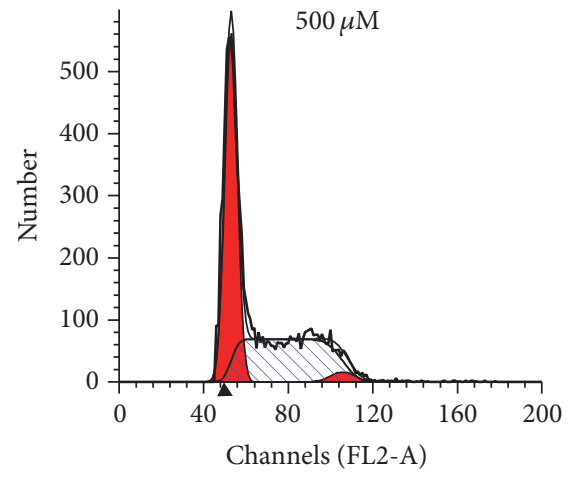

$\square$ Dip G0-G1

$\square$ Dip G2-M

$\square$ Dip S

(c)

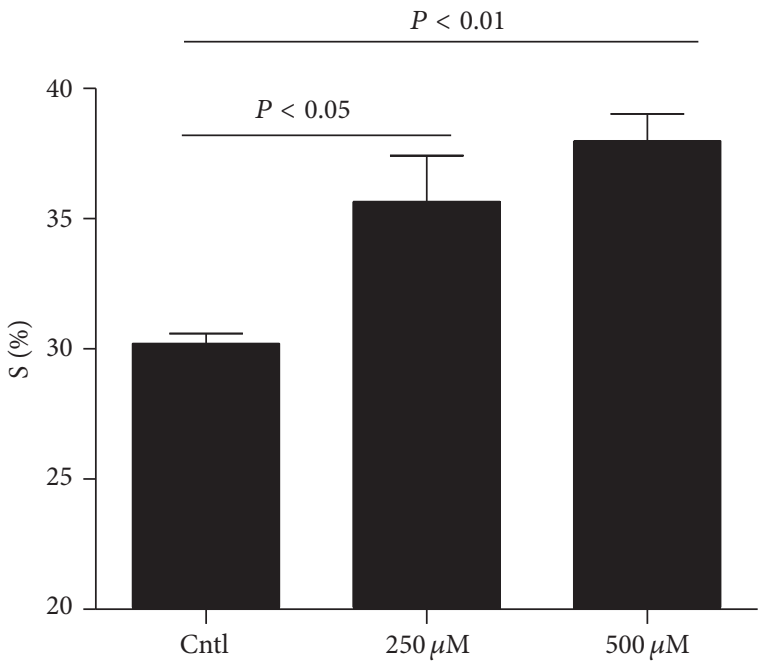

(e)

$P<0.01$

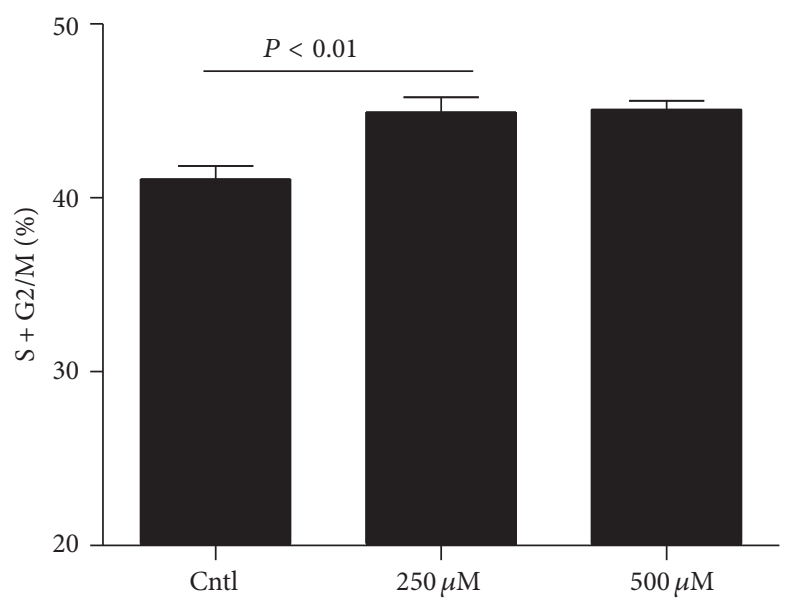

(f)

FIGURE 2: Effect of IS on cell cycle progression in MCs. The percentage of cells at different cell cycle phases was detected by flow cytometry after MCs were treated with the indicated doses of IS for $24 \mathrm{~h}$. (a-c) Representative images of cell cycle with different doses of IS. (d-f) Percentage of cells at S, G1/G0, and (S + G2)/M phases. Values are means $\pm \mathrm{SD} ; n=6$ in each group. 


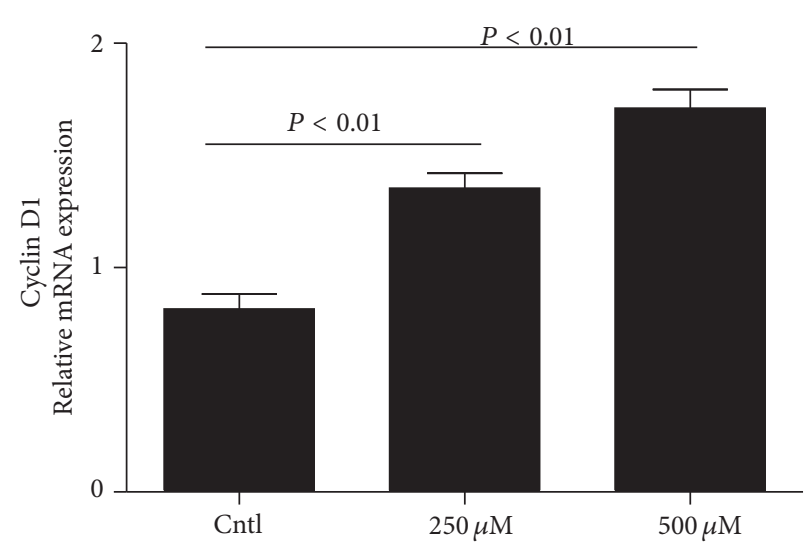

(a)

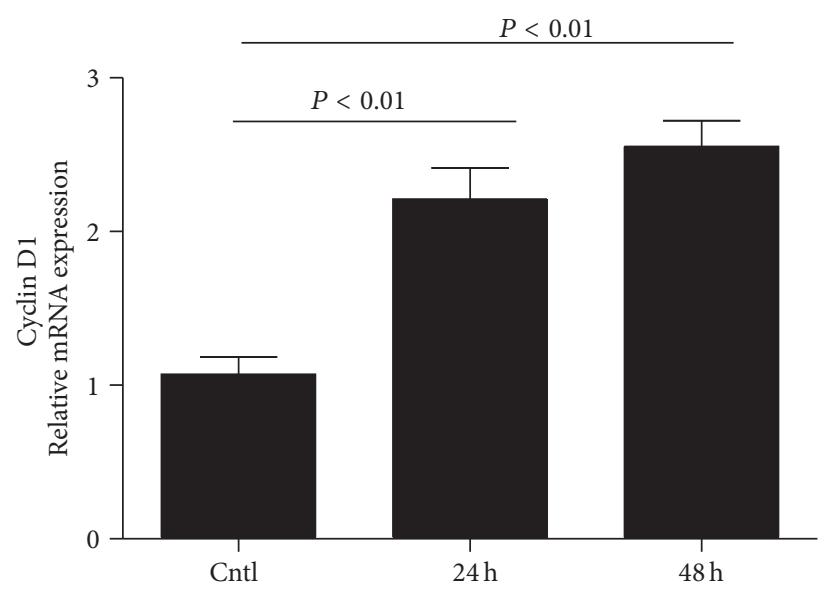

(c)

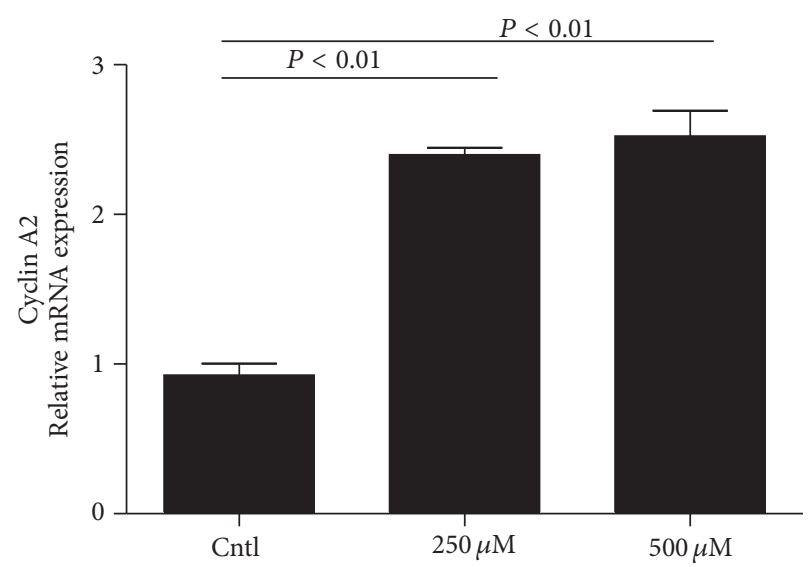

(b)

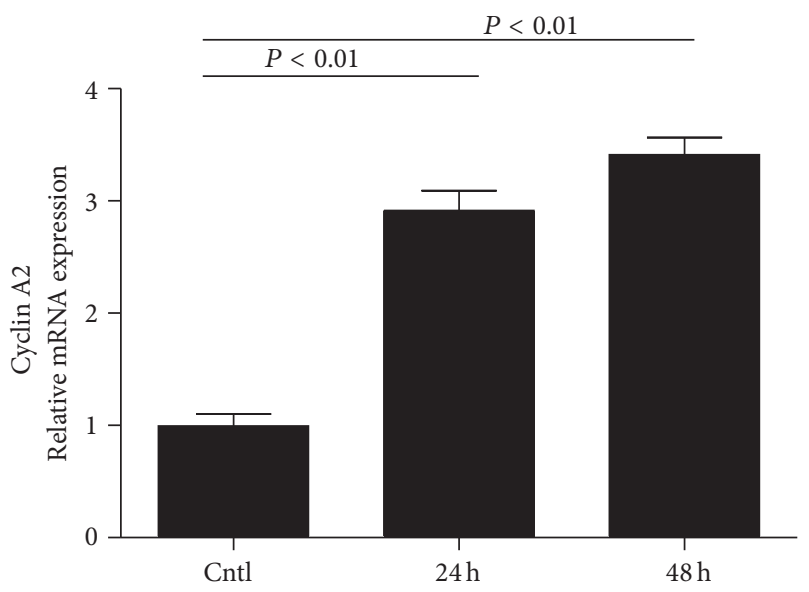

(d)

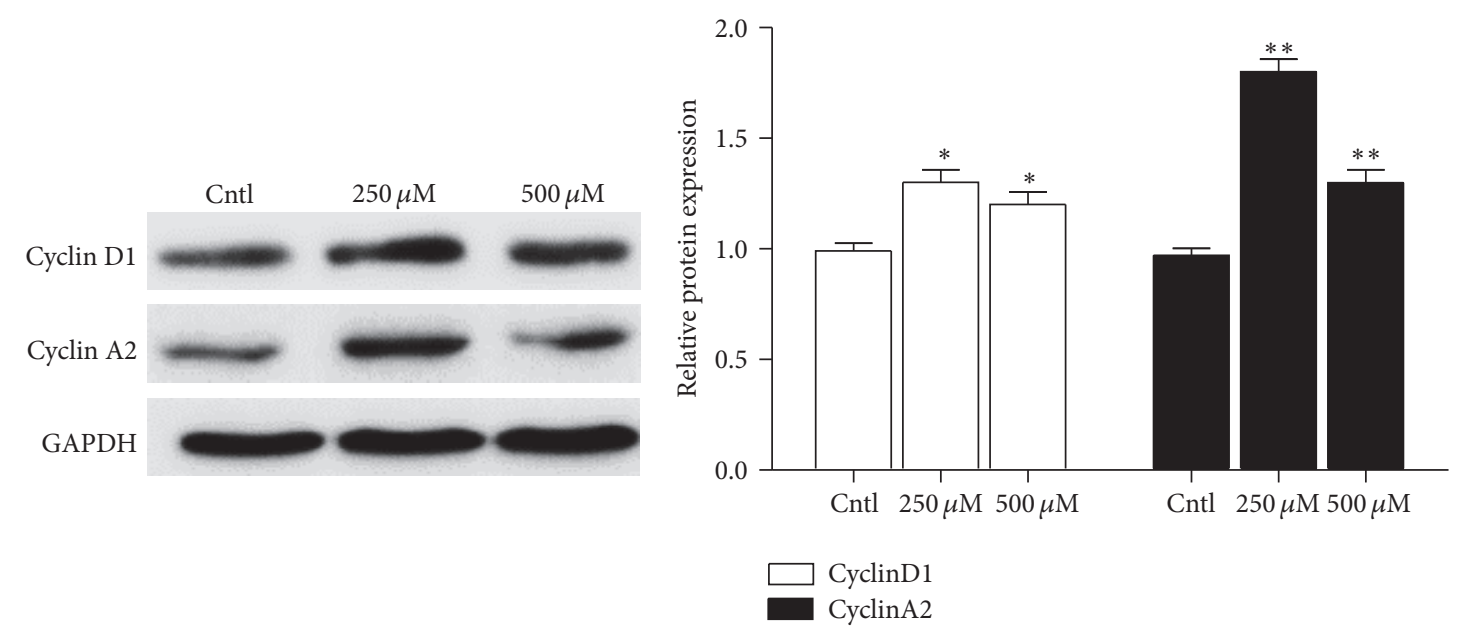

(e)

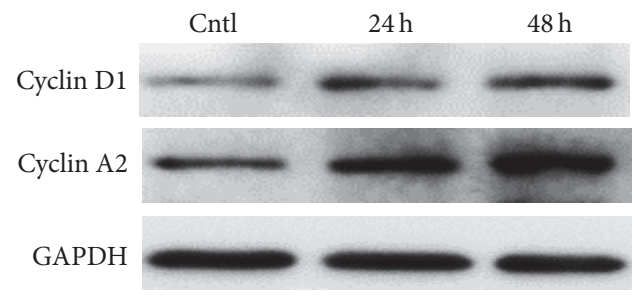

(g)

FIgure 3: Continued. 


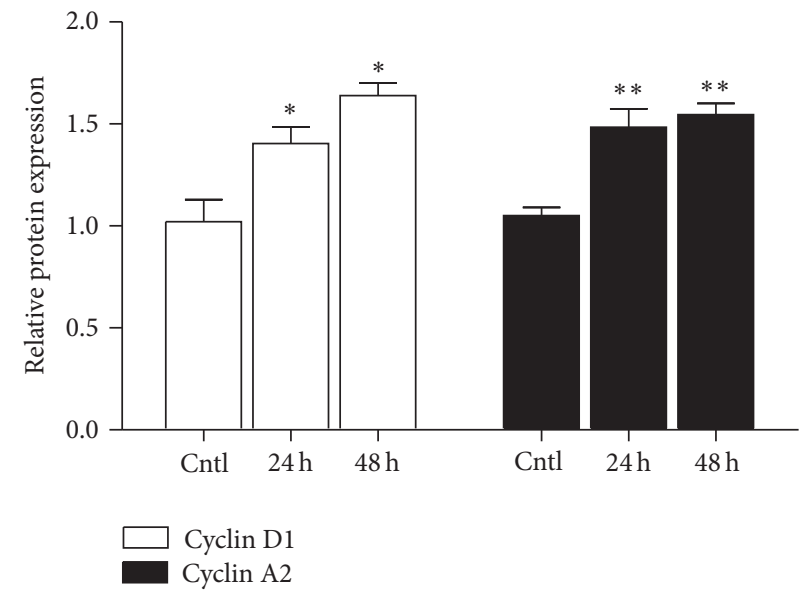

(h)

FIGURE 3: Effects of IS on the expressions of cyclin D1 and cyclin A2 in MCs. After MCs were treated with IS, cyclin D1 (a) and cyclin A2 (b) mRNA levels were elevated in a dose-dependent manner following $24 \mathrm{~h}$ treatment. Meanwhile, a time-dependent induction of cyclin D1 and cyclin A2 mRNA expressions was tested ( $c$ and d). Protein levels of cyclin D1 and cyclin A2 were also detected using dose- and time-dependent experiments $(\mathrm{e}-\mathrm{h})$. All values are means $\pm \mathrm{SD} ; n=6$ in each group; ${ }^{*} P<0.05$ versus control and ${ }^{* *} P<0.01$ versus control.

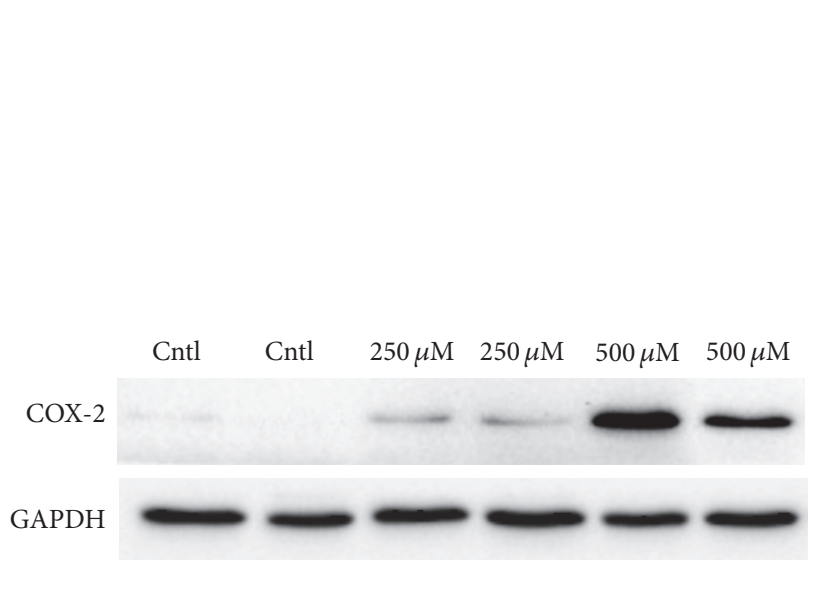

(a)

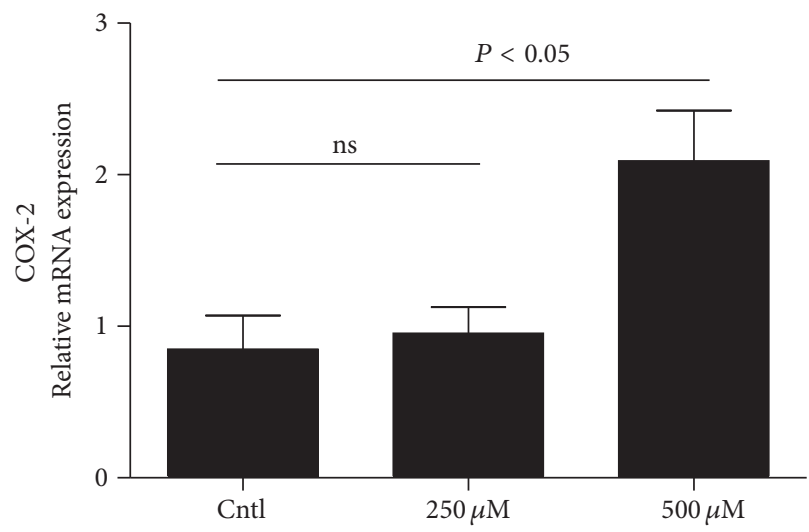

(c)

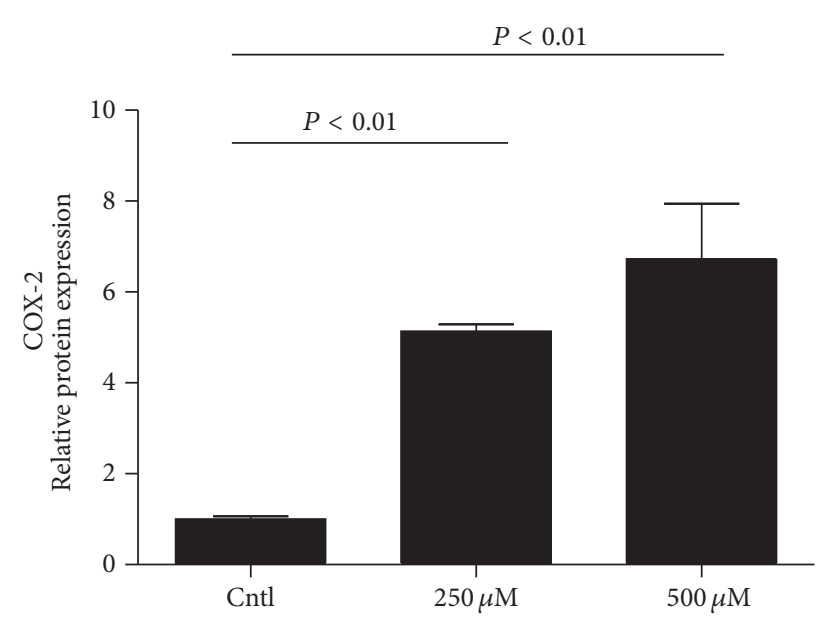

(b)

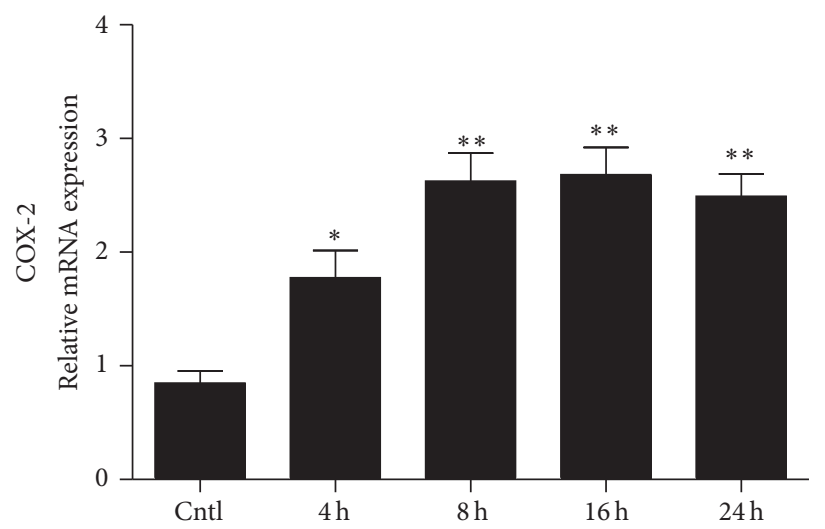

(d)

FIgURE 4: Expression of COX-2 in IS-induced mouse MCs. MCs were treated with the indicated doses of IS (0, 250, and 500 $\mu \mathrm{M})$ for $24 \mathrm{~h}$ and then COX-2 protein ( $\mathrm{a}$ and $\mathrm{b}$ ) and mRNA (c) and protein expressions were analyzed by Western blotting and qRT-PCR. A time course analysis of COX-2 mRNA expression following IS treatment at a dose of $500 \mu \mathrm{M}$ was also examined (d). Values are means \pm SD; $n=6$ in each group; ${ }^{*} P<0.05$ versus control and ${ }^{* *} P<0.01$ versus control. 


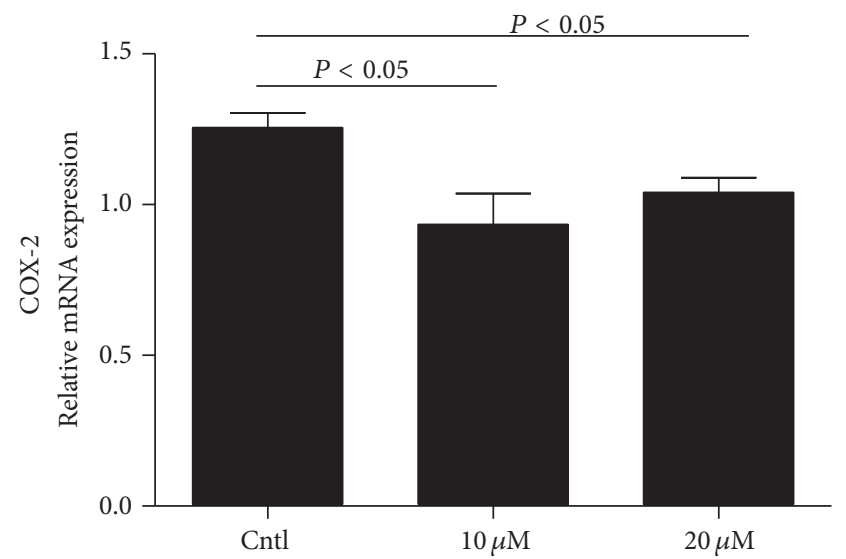

(a)

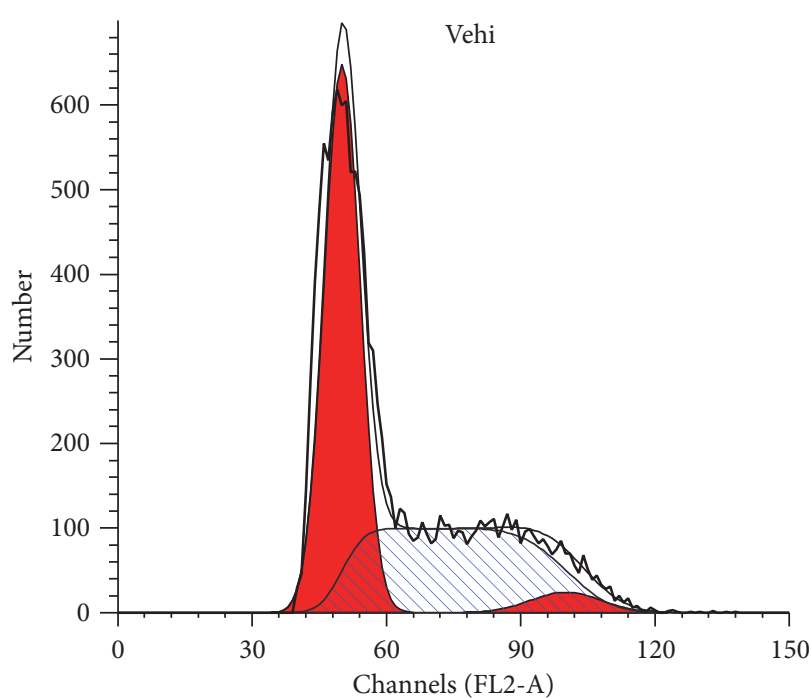

$\square$ Dip G0-G1

$\square$ Dip G2-M

(c)

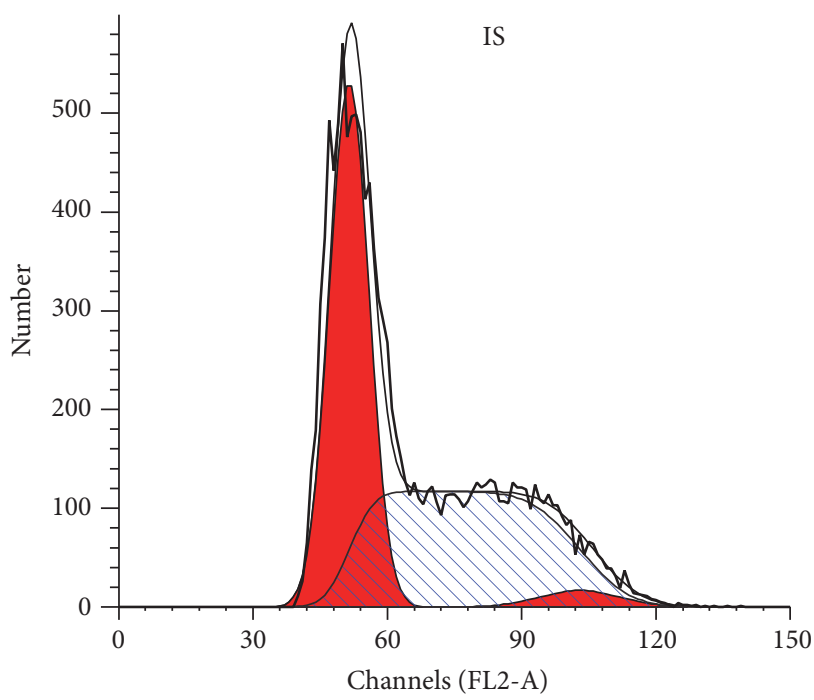

Dip G0-G1

$\square$ Dip G2-M

$\square$ Dip S 


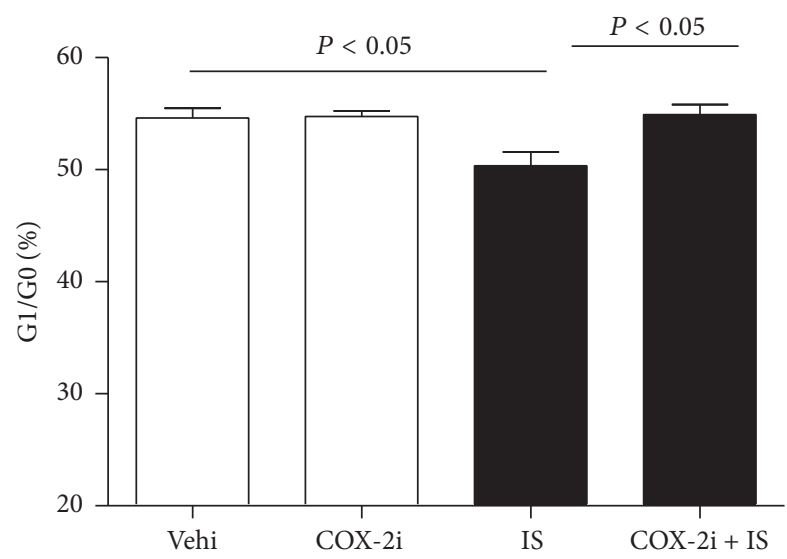

(g)

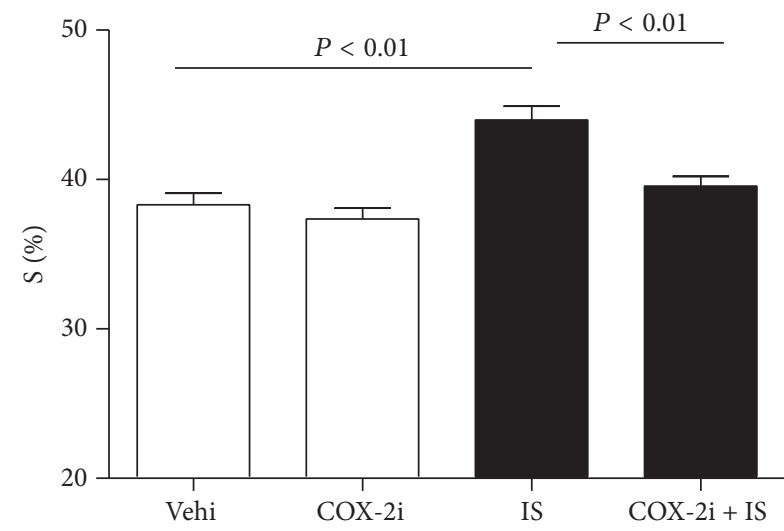

(i)

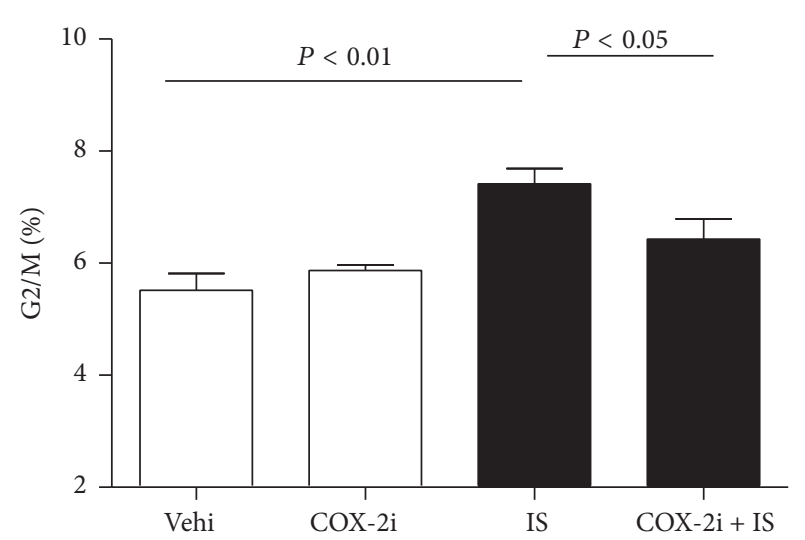

(h)

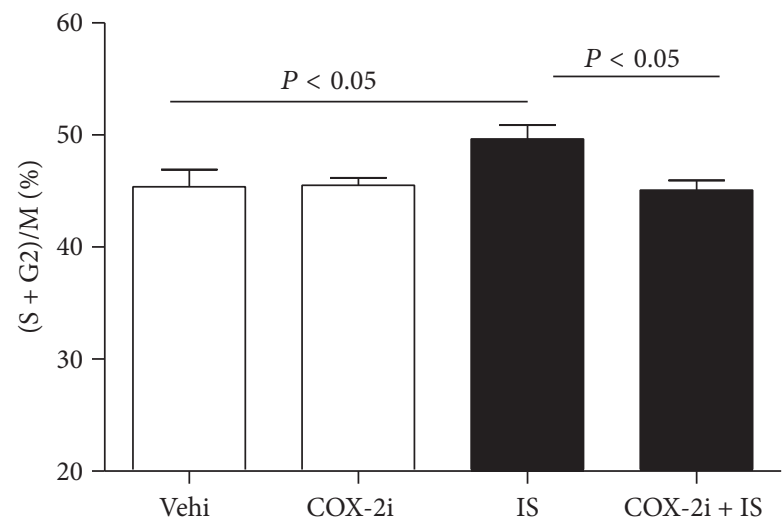

$(\mathrm{j})$

Figure 5: Effects of COX-2 specific inhibitor NS398 on cell cycle progression after IS treatment. The cells were treated with NS398 (10 $\mu$ M) for $12 \mathrm{~h}$ before IS $(500 \mu \mathrm{M})$ administration. (a) qRT-PCR analysis of COX-2 after COX-2 inhibitor (NS398, $10 \mu \mathrm{M}$, and $20 \mu \mathrm{M})$ treatment in MCs. (b) Western blotting analysis of COX-2 expression after COX-2 inhibitor (10 $\mu \mathrm{M}$ and $20 \mu \mathrm{M})$ treatment in MCs. (c-f) Representative images of cell cycle following the treatments of IS and/or COX-2 inhibitor. (g-j) Percentage of cells at G1/G0 (g), G2/M (h), S (i), and (S + $\mathrm{G} 2) / \mathrm{M}(\mathrm{j})$ phases following the treatments of IS and/or COX-2 inhibitor. Values are means $\pm \mathrm{SD} ; n=6$ in each group.

Cell proliferation is ultimately regulated at cell cycle process including four stages of G1, S, G2, and M with important checkpoints in G1 and G2. Cyclin D1 controls cell cycle progression through the G1 phase and G1-to-S transition [20], and cyclin A-associated kinase activity is required for the entry into $S$, completion of $S$, and entry into $\mathrm{M}$ phase [21]. Thus the expressions of cyclin D1 and cyclin A2 were chosen as markers for cell cycle progression. Doseresponse experiments showed that IS significantly induced cyclin A2 and cyclin D1 expression in MCs consistent with the results which were demonstrated in rat MCs [22]. Similarly, the increase of cell numbers in the $S$ phase was also observed following IS treatment. These findings highly suggested that IS served as a contributor of cell cycle progression and cell proliferation in MCs.

Next, we examined the possible mechanism mediating IS effect on MC proliferation. By reviewing the literature, recent evidence indicated that an inducible inflammatory enzyme COX-2 can be induced in MCs in response to sphingosine 1-phosphate stimulation [18]. Following this notion, we examined the regulation of COX-2 in MCs following
IS treatment. Interestingly, IS remarkably elevated COX2 expression at both mRNA and protein levels in doseand time- dependent manners. Meantime, IS also elevated PGE2 production. These data indicated that IS could directly stimulate COX-2 upregulation and PGE2 induction in MCs. In order to further define the role of COX-2 in this cell cycle progression, COX-2 specific inhibitor was applied to the cells before IS administration. As expected, COX-2 inhibitor blunted the COX-2 expression. Meanwhile, reduction of cell cycle-related proteins of cyclin D1 and A2 was also significantly attenuated by COX-2 inhibition in line with a blockade of PGE2 induction.

All these data indicated a significant role of IS in promoting MC proliferation via activating COX-2. The proliferation of MCs has to be attributable to the progressive impairment of residual nephrons, as well as the loss of RRF in ESRD patients to some extent. Considering the important role of RRF in maintaining a better homeostasis of internal environment and better life quality of patients, targeting IS and COX-2 might be useful for the preservation of RRF. 


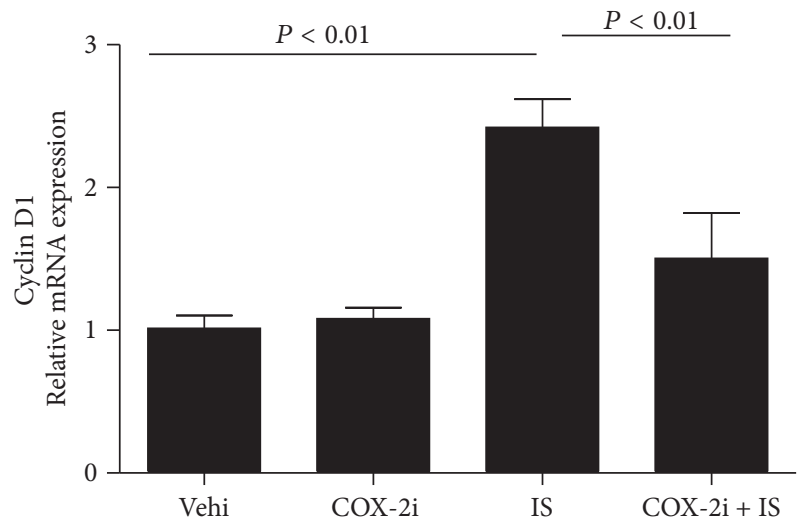

(a)

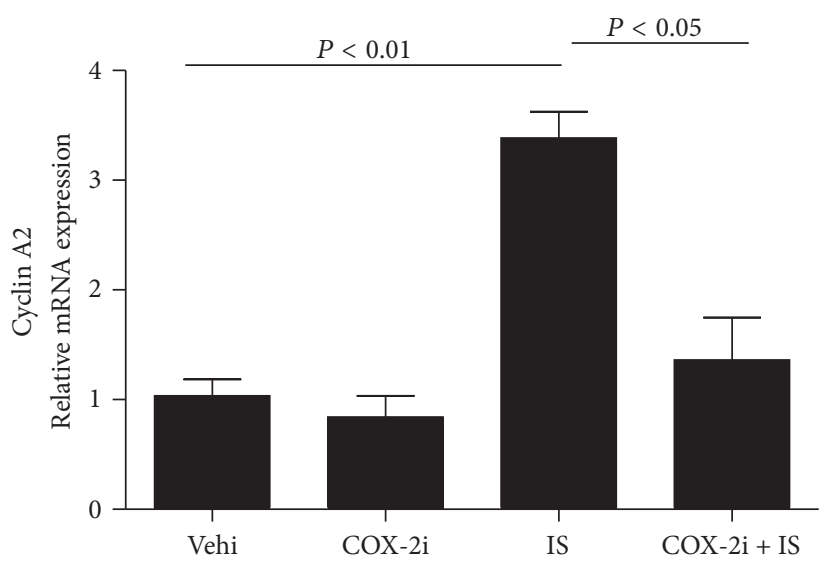

(b)

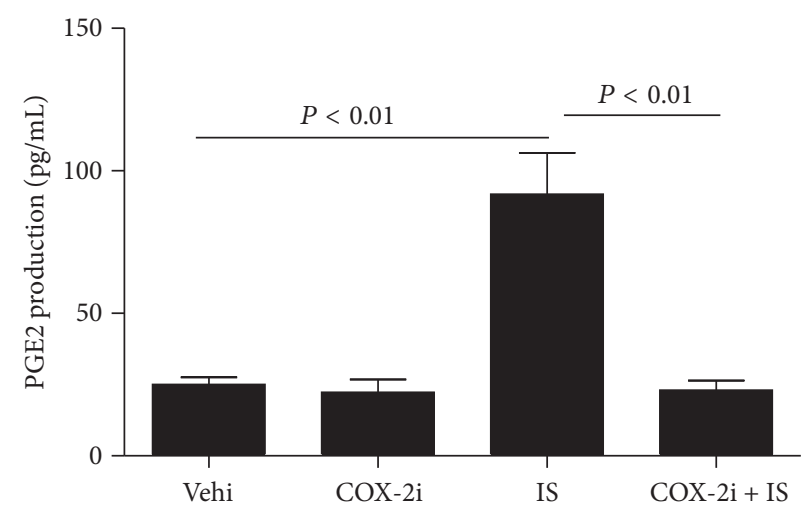

(c)

FIGURE 6: Effects of COX-2 inhibition on the mRNA expressions of cyclin D1 and cyclin A2 and the production of PGE2. (a) mRNA expression of cyclin D1 determined by qRT-PCR; (b) mRNA expression of cyclin A2 determined by qRT-PCR; (c) enzyme immunoassay of PGE2 in the medium. Values are means $\pm \mathrm{SD} ; n=6$ in each group.

\section{Competing Interests}

The authors declare that there is no conflict of interests.

\section{Authors' Contributions}

Shuzhen Li and Sijie Cheng equally contributed to this work.

\section{Acknowledgments}

This work was supported by Grants from the National Natural Science Foundation of China (nos. 81370802, 81300591, 81670647, and 81570616), the National Key Research and Development Program (no. 2016YFC0906103), and the Natural Science Foundation of Jiangsu Province (no. BK2012001).

\section{References}

[1] P. Tam, "Peritoneal dialysis and preservation of residual renal function," Peritoneal Dialysis International, vol. 29, supplement 2, pp. S108-S110, 2009.

[2] J. M. Bargman, K. E. Thorpe, and D. N. Churchill, "Relative contribution of residual renal function and peritoneal clearance to adequacy of dialysis: a reanalysis of the canusa study," Journal of the American Society of Nephrology, vol. 12, no. 10, pp. 21582162, 2001.

[3] C. C. Szeto, T. Y. Wong, C. B. Leung et al., "Importance of dialysis adequacy in mortality and morbidity of chinese CAPD patients," Kidney International, vol. 58, no. 1, pp. 400-407, 2000.

[4] R. Paniagua, D. Amato, E. Vonesh et al., "Effects of increased peritoneal clearances on mortality rates in peritoneal dialysis: ADEMEX, a prospective, randomized, controlled trial," Journal of the American Society of Nephrology, vol. 13, no. 5, pp. 13071320, 2002.

[5] N. M. Pham, N. S. Recht, T. H. Hostetter, and T. W. Meyer, "Removal of the protein-bound solutes indican and P-cresol sulfate by peritoneal dialysis," Clinical Journal of the American Society of Nephrology, vol. 3, no. 1, pp. 85-90, 2008.

[6] T. Niwa, "Uremic toxicity of indoxyl sulfate," Nagoya Journal of Medical Science, vol. 72, no. 1-2, pp. 1-11, 2010.

[7] T. Niwa, N. Takeda, A. Tatematsu, and K. Maeda, "Accumulation of indoxyl sulfate, an inhibitor of drug-binding, in uremic serum as demonstrated by internal-surface reversedphase liquid chromatography," Clinical Chemistry, vol. 34, no. 11, pp. 2264-2267, 1988.

[8] T. Niwa and M. Ise, "Indoxyl sulfate, a circulating uremic toxin, stimulates the progression of glomerular sclerosis," Journal of Laboratory and Clinical Medicine, vol. 124, no. 1, pp. 96-104, 1994. 
[9] T. Niwa, T. Yazawa, M. Ise et al., "Inhibitory effect of oral sorbent on accumulation of albumin-bound indoxyl sulfate in serum of experimental uremic rats," Nephron, vol. 57, no. 1, pp. 84-88, 1991.

[10] T. Niwa, Y. Emoto, K. Maeda, Y. Uehara, N. Yamada, and M. Shibata, "Oral sorbent suppresses accumulation of albuminbound indoxyl sulphate in serum of haemodialysis patients," Nephrology Dialysis Transplantation, vol. 6, no. 2, pp. 105-109, 1991.

[11] A. K. Gelasco and J. R. Raymond, "Indoxyl sulfate induces complex redox alterations in mesangial cells," American Journal of Physiology-Renal Physiology, vol. 290, no. 6, pp. F1551-F1558, 2006.

[12] M. Yisireyili, S. Saito, S. Abudureyimu et al., "Indoxyl sulfateinduced activation of (pro)renin receptor promotes cell proliferation and tissue factor expression in vascular smooth muscle cells," PLoS ONE, vol. 9, no. 10, Article ID e109268, 2014.

[13] J. Floege, E. Eng, B. A. Young, and R. J. Johnson, "Factors involved in the regulation of mesangial cell proliferation in vitro and in vivo," Kidney International-Supplement, vol. 39, pp. S47S54, 1993.

[14] R. C. Harris, J. A. McKanna, Y. Akai, H. R. Jacobson, R. N. Dubois, and M. D. Breyer, "Cyclooxygenase-2 is associated with the macula densa of rat kidney and increases with salt restriction," Journal of Clinical Investigation, vol. 94, no. 6, pp. 2504-2510, 1994.

[15] B. Rodríguez-Iturbe and G. García García, "The role of tubulointerstitial inflammation in the progression of chronic renal failure," Nephron Clinical Practice, vol. 116, no. 2, pp. c81-c88, 2010.

[16] Z. Jia, N. Wang, T. Aoyagi, H. Wang, H. Liu, and T. Yang, "Amelioration of cisplatin nephrotoxicity by genetic or pharmacologic blockade of prostaglandin synthesis," Kidney International, vol. 79, no. 1, pp. 77-88, 2011.

[17] S. Frölich, A. Olliges, N. Kern, Y. Schreiber, S. Narumiya, and R. M. Nüsing, "Temporal expression of the $\mathrm{PGE}_{2}$ synthetic system in the kidney is associated with the time frame of renal developmental vulnerability to cyclooxygenase-2 inhibition," American Journal of Physiology - Renal Physiology, vol. 303, no. 2, pp. F209-F219, 2012.

[18] A. Völzke, A. Koch, D. Meyer Zu Heringdorf, A. Huwiler, and J. Pfeilschifter, "Sphingosine 1-phosphate (S1P) induces COX2 expression and PGE2 formation via S1P receptor 2 in renal mesangial cells," Biochimica et Biophysica Acta-Molecular and Cell Biology of Lipids, vol. 1841, no. 1, pp. 11-21, 2014.

[19] T. Niwa, "Indoxyl sulfate is a nephro-vascular toxin," Journal of Renal Nutrition, vol. 20, no. 5, supplement, pp. S2-S6, 2010.

[20] F. S. Pardo, M. Su, and C. Borek, "Cyclin D1 induced apoptosis maintains the integrity of the G1/S checkpoint following ionizing radiation irradiation," Somatic Cell and Molecular Genetics, vol. 22, no. 2, pp. 135-144, 1996.

[21] F. Girard, U. Strausfeld, A. Fernandez, and N. J. C. Lamb, “Cyclin $A$ is required for the onset of DNA replication in mammalian fibroblasts," Cell, vol. 67, no. 6, pp. 1169-1179, 1991.

[22] Y. Zhuang, Q. Feng, G. Ding et al., "Activation of ERK1/2 by $\mathrm{NADPH}$ oxidase-originated reactive oxygen species mediates uric acid-induced mesangial cell proliferation," American Journal of Physiology-Renal Physiology, vol. 307, no. 4, pp. F396F406, 2014. 


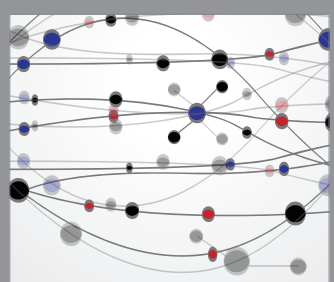

The Scientific World Journal
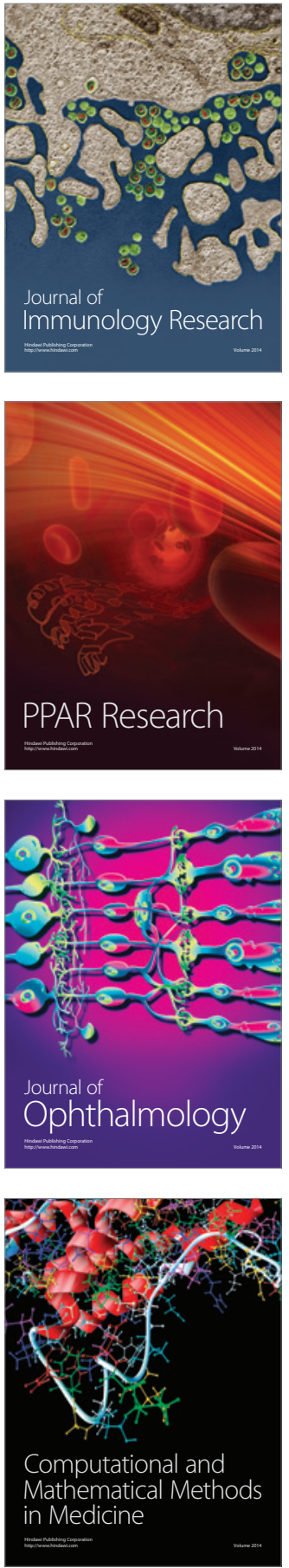

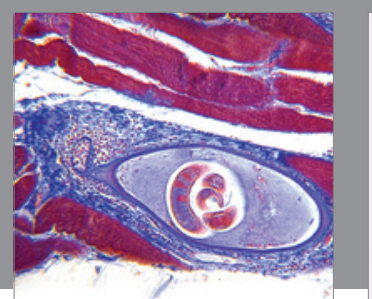

Gastroenterology Research and Practice

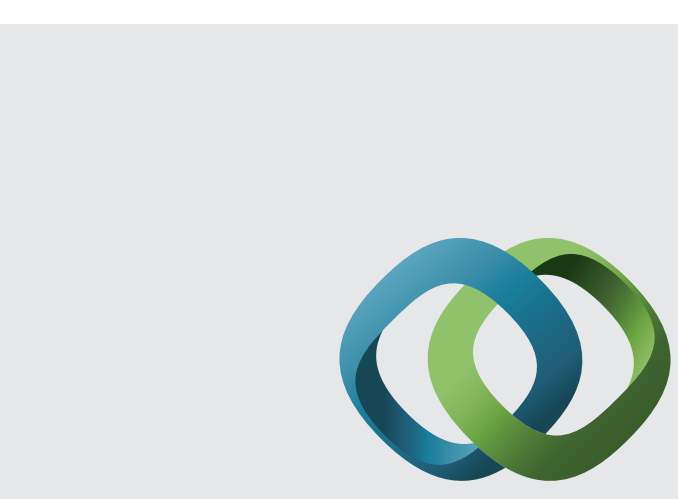

\section{Hindawi}

Submit your manuscripts at

http://www.hindawi.com
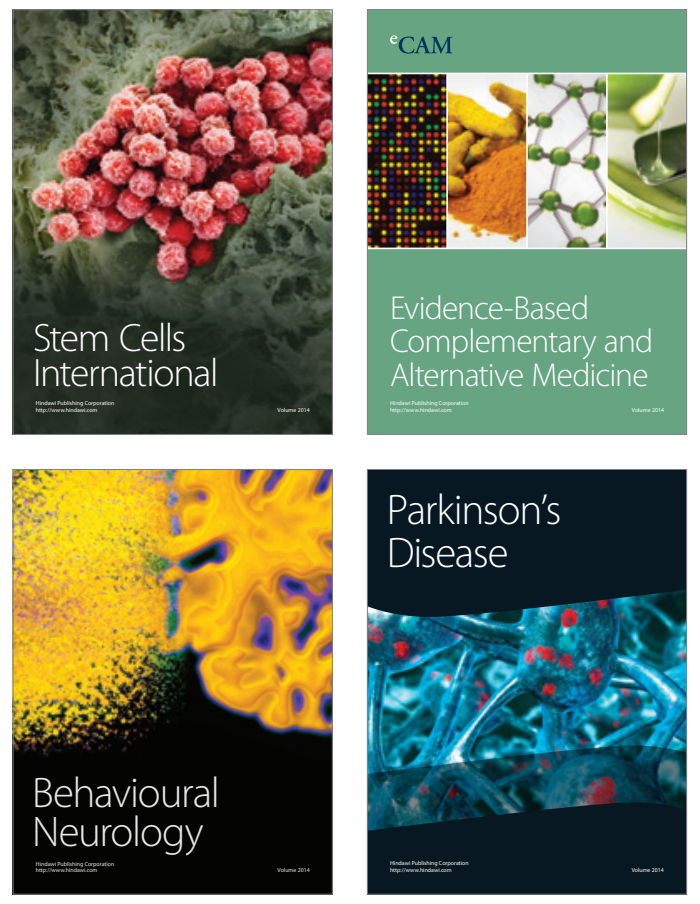
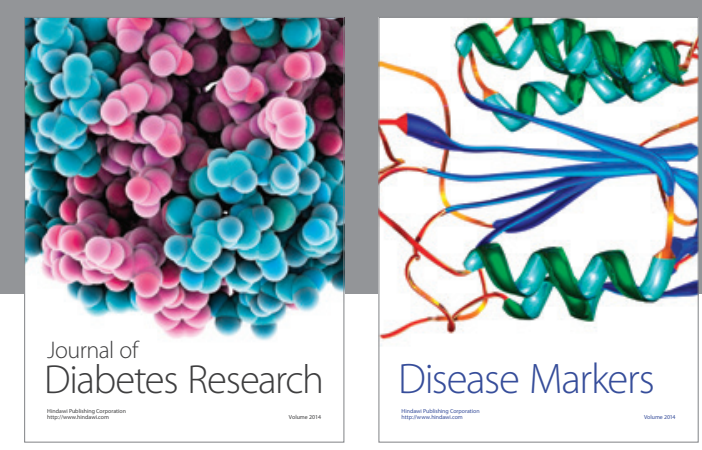

Disease Markers
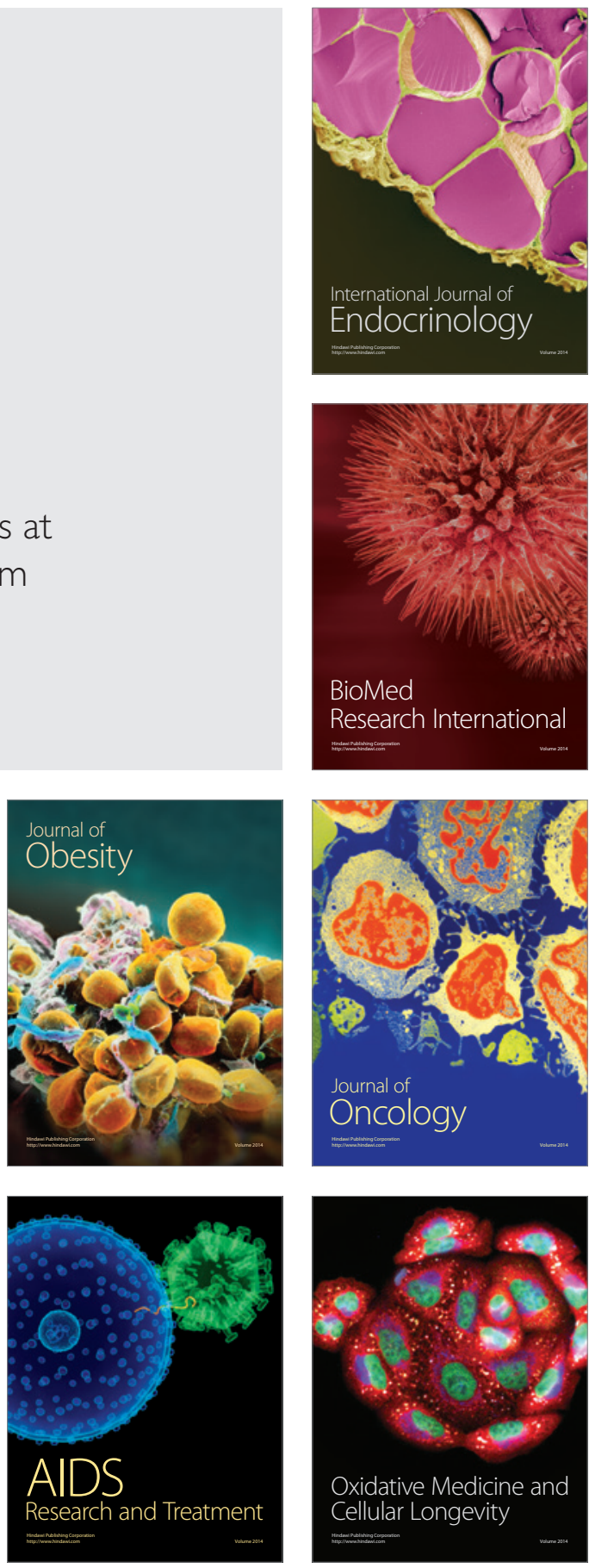